\title{
Estrategia de posicionamiento del destino Villa Clara en el mercado chino
}

DOI: $10.22403 /$ UQROOMX/TYP07/03

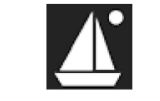

RESUMEN

Yanet Hernández Aro

Esther Lidia Machado Chaviano Universidad Central "Marta Abreu" de Las Villas

El desarrollo económico alcanzado a finales del siglo pasado y a comienzos de éste se ha caracterizado por el avance del sector terciario de la economía, favorecido en gran parte por el auge económico, la modernización de los medios de transporte y de las comunicaciones, y por ser considerado un medio para incrementar el desarrollo en general; la actividad turística se ha convertido especialmente en la industria de mayores proporciones y crecimiento anual en numerosos países. China ha impulsado el turismo a un ritmo más acelerado que el resto de los países, representa un mercado emisor importante que ofrece grandes oportunidades para destinos turísticos en desarrollo como Villa Clara (Cuba), el cual posee interesantes y singulares recursos turísticos naturales, históricos y culturales, pero carece de un posicionamiento definido en este mercado. La presente investigación aborda el problema del posicionamiento del destino turístico Villa Clara en el mercado chino, con el objetivo de elaborar estrategias efectivas para aumentar la demanda.

Palabras |Villa Clara, atractivos turísticos, marketing, mercado emisor CLAVE chino, posicionamiento, producto turístico, turismo. 
Estrategia de posicionamiento

del destino Villa Clara en el mercado chino

\section{Introducción}

El turismo es una de las industrias que experimenta un mayor crecimiento mundial, lo cual tiene un efecto relevante en diversos campos: la economía, la sociedad, la cultura y el medio ambiente. Su repercusión en la economía es muy importante, ya que aporta $10.6 \%$ del producto interno bruto mundial y da empleo a 230 millones de personas (I0\% de la población laboral) (OMT, 1996).

Este crecimiento y la continua tarea de satisfacer a los clientes han dado como resultado que la industria de la hospitalidad se vuelva cada vez más competitiva, lo que significa que, para tener éxito en el mercado actual, las empresas prestadoras de servicios turísticos deben centrarse en el cliente, buscando la forma de atraerlo y conservarlo.

Entre los principales países que han marcado esta acelerada tendencia se encuentra China, que en poco tiempo ha penetrado en gran escala el turismo global. Los numerosos turistas chinos que pasan sus vacaciones más allá de sus fronteras han despertado un entusiasmo turístico sin precedentes. Si los pronósticos actuales llegan a confirmarse, se registrarán proporciones nunca antes vistas en el plano mundial respecto a este importante mercado emisor.

Por ello, el creciente desarrollo de este mercado representa para el destino turístico de Villa Clara la oportunidad de absorber parte del mercado emisor chino, teniendo en cuenta sus particularidades, pero también los recursos de los cuales dispone, siendo los fundamentales sus magníficos cayos con paradisiacas playas y su patrimonio histórico-cultural que complementa todos los atractivos naturales del territorio.

Para lograr este propósito, será necesario realizar de inmediato reajustes en las políticas y estrategias orientadas a captar una buena parte del mercado turístico chino así como a satisfacer su demanda. Ante ello, el presente trabajo se plantea como objetivo elaborar una estrategia efectiva para el posicionamiento de la oferta del destino turístico Villa Clara en el mercado chino, a partir de un análisis teórico-conceptual y de la identificación de los atractivos turísticos disponibles en el destino, así como de las particularidades de la oferta hotelera, junto con las condiciones internas y competitivas, y los problemas más significativos que afectan el posicionamiento del destino objeto de estudio, teniendo en cuenta la caracterización del mercado emisor chino. 


\section{Concepciones básicas}

El turismo es entendido como el conjunto de fenómenos y relaciones económicas, psicosociológicas y medioambientales que se establecen entre el destino emisor y el lugar de destino, donde se generan los servicios y productos, según los motivos del viaje y la estancia temporal del visitante en un lugar diferente al de su residencia habitual.

El marketing es el arte de saber qué producir y vender, a partir de las necesidades y deseos del consumidor, teniendo como fin la satisfacción tanto para el consumidor como para la entidad o empresa. Hoy se ha convertido en un imperativo competitivo la aplicación de una filosofía moderna de marketing en la gestión de la empresa turística y en la planificación de los destinos turísticos. Para ello es preciso establecer la estrategia comercial, constituida por tres elementos clave que configuran el denominado triángulo estratégico: mercado, producto y competencia.

El producto constituye la base de todo el sistema de marketing. El producto turístico está conformado por aquellas ofertas de distintos tipos, que se preparan para ser brindadas al turista mediante el empleo de diferentes tecnologías, que resultan capaces de motivar visitas a determinados lugares y satisfacer un interés o necesidad específicos.

Los atractivos turísticos son la base de los productos turísticos o modalidades turísticas, como también se les denomina, y la motivación es la causa del viaje -un conjunto de actividades que desarrollar-, lo cual enlaza las motivaciones con las modalidades turísticas. Hoy existen multimotivaciones (las personas viajan con más de un propósito a la vez), por lo que se deben preparar multiproductos para lograr la más amplia satisfacción.

El posicionamiento es el lugar que ocupa el producto en la mente del consumidor; además, es un indicador de la percepción del cliente sobre nuestro producto y mezcla de marketing en comparación con los demás productos existentes en el mercado.

\section{Características generales de Villa Clara y del mercado turístico chino}

Villa Clara es un atractivo destino turístico de sol y playa, histórico, cultural y de salud, que dispone de los recursos necesarios para continuar su crecimiento 
Estrategia de posicionamiento

del destino Villa Clara en el mercado chino

e incluso desarrollar segmentos alternativos para posicionarse de manera efectiva ante la creciente competitividad del sector.

Entre sus principales fortalezas se encuentran tanto su imagen asociada con la figura del Che Guevara, lo cual le da un distintivo único a la ciudad de Santa Clara -materializado en sus monumentos-, como el reconocimiento de Cuba en cuanto destino turístico de sol y playa, seguro y tranquilo, mientras que entre sus debilidades están la escasa promoción de sus recursos turísticos culturales, así como una red hotelera en la ciudad de Santa Clara carente de atractivos y de diversificación, de baja calidad y poca variedad de servicios turísticos (restauración, guía, información).

Las causas fundamentales que permiten el crecimiento sostenido del turismo emisor chino son, entre otras, el aumento del poder adquisitivo, el envejecimiento de la población, la ventaja en el tipo de cambio, la salida de divisas y las altas tasas de ahorro (López Alberca, 2006). China muestra un incremento sostenido de su economía, y la actividad turística ha cobrado relevancia dado el acelerado crecimiento de su demanda como destino turístico -actualmente ocupa el cuarto lugar en la preferencia mundial-, pero también por ser un mercado emisor con alto potencial, lo que justifica la necesidad de desplegar estrategias para posicionar al destino turístico objeto de estudio.

Los factores esenciales que el turista chino considera al elegir un destino son la seguridad y limpieza del lugar, el grado de interés que éste proporciona, el acercamiento a una cultura diferente, el contacto directo con la naturaleza y el conocimiento de sitios históricos.

\section{Estrategias para posicionar Villa Clara en el mercado turístico chino}

La propuesta para posicionar el destino turístico de Villa Clara en el mercado emisor chino se basa tanto en el procedimiento planteado por Lovelock (1997) como en las particularidades de este mercado.

\section{Análisis del mercado}

Según la China National Tourism Administration (CNTA), en 2004 viajaron al exterior 28 millones de turistas, lo cual representa un incremento de $43 \%$ 
respecto al 2003, gastando en los destinos 30.8 billones de dólares. En 2005, había viajado $2 \%$ de la población china llegando a $10 \%$ de la población si se toman en consideración las tres principales ciudades chinas.

En el primer trimestre del 2006 salieron al exterior 8.52 millones de turistas -lo cual constituye un incremento de $16.33 \%$ respecto al mismo periodo del año anterior-, de los cuales 7.2 millones lo hicieron con pasaporte privado, dándose un incremento de $20.46 \%$ en relación con el periodo anterior (López Alberca, 2006).

En 2005, el número total de turistas emitidos por China fue de 31026300 , con un aumento de $7.5 \%$; 5886300 personas (19\%) en viajes oficiales, experimentando un incremento de $0.2 \%$. Los viajes privados representan $81 \%$ ( 25 I 40000 personas), con un crecimiento de $9.4 \%$, según datos proporcionados por la CNTA y que coinciden con los de la Organización Mundial del Comercio (OMC -WTO, por sus siglas en inglés-).

De acuerdo con la OMC, se espera que en 2010 los turistas emitidos lleguen a 50 millones y para el 2020 alcancen los 100 millones, situándose como el cuarto mercado emisor del mundo. Las cifras varían según las fuentes, pero siempre son elevadas.

Definición y análisis de los segmentos de mercado

Perfil del viajero

a) Motivación. El tipo de visado solicitado por el viajero chino, que en el pasado era mayormente de negocios o estudios (non private purpose), está pasando a ser de ocio (private purpose) (López Alberca, 2006).

b) Sexo. Según el estudio "Understanding the Chinese Traveller", de la consultora ACNielsen (2005), respecto al sexo de la población que viaja al exterior, $31 \%$ es masculina y $69 \%$ femenina. Estos datos difieren de otras fuentes consultadas, donde se habla de $50 \%$ para cada sexo.

c) Edad. ACNielsen (2005) también afirma que más de $50 \%$ de la población que viaja está por debajo de los 40 años, es decir, constituye un mercado joven.

d) Tamaño del grupo. En general, al turista chino le gusta viajar en grupo, por diferentes motivos: culturales, por la percepción de que es más económico, se sienten más seguros, por tradición familiar; etc. Si bien 
Estrategia de posicionamiento

del destino Villa Clara en el mercado chino

no está estandarizada una medida, viajan en grupos de cinco personas como mínimo.

e) Composición del grupo. La composición del grupo es heterogénea, siguiendo el perfil familiar.

f) Frecuencia de viajes. Según la CNTA, $42 \%$ de los turistas emitidos pasean por primera vez fuera de sus fronteras, lo cual demuestra una alta predisposición del nuevo turista chino para salir de su nación.

Aspectos cualitativos de la demanda

a) Elección del destino:

- Asia: principal destino turístico de los chinos por su cercanía geográfica, su similitud cultural y reducido precio. Dentro de este mercado, los destinos preferidos son, en orden de importancia, Singapur, Tailandia, Japón y Corea; son relevantes también las regiones especiales de Hong Kong-Macao, elegidas por $67.7 \%$ como promedio. Entre otras cosas, este alto porcentaje se explica por la proximidad geográfica y cultural,y por los sencillos requisitos formales que exigen las autoridades encargadas en estos destinos.

- Europa: segundo destino turístico. El mercado está en fase embrionaria tras la reciente incorporación a la lista de países con la categoría de destino turístico aprobado (ADS). El mercado europeo presenta a priori un gran atractivo para el turista chino debido a la diferencia cultural, lo misterioso y desconocido de la civilización y su larga historia, la belleza de los parajes, la abundancia de museos y obras de arte, la multitud de lugares de fama mundial -ya sea por acontecimientos históricos o por ser objeto de películas de difusión en todo el mundo-, la calidad de los servicios turísticos y de la infraestructura. Pero, en la práctica, el turista chino no está maduro y lo que más llama su atención en su primera visita a Europa son las zonas comerciales y los lugares más populares. Es hasta una segunda visita, en los denominados viajes de repetición, cuando se interesa en el patrimonio cultural.

- América: ni Estados Unidos (primer destino turístico del mundo) ni Canadá están catalogrados como ADS, con lo que a la hora de viajar a estos países ha de hacerse con la visa de negocios, estudios o visitas 
a familiares. Sólo Cuba dispone del ADS, y el número de turistas chinos que reporta es aún insignificante.

b) Servicios que compran. Los servicios que estos turistas contratan en sus paquetes son billete, impuestos, aeropuerto, hotel, desayuno, comidas, transporte interior y guía turístico. Cabe destacar, como se ha comentado en otros puntos, que contratan los servicios más baratos, siendo muy elásticos a las variaciones de precios.

c) Estacionalidad. El mercado presenta una fuerte estacionalidad centrada en las semanas doradas, en general, únicos periodos permitidos por el gobierno central para tomar vacaciones. Periodos de una semana o cinco días en torno a las siguientes fechas: Fiesta de Primavera (que se celebra a finales de enero o principios de febrero, en función del calendario lunar y es la época de mayores salidas al extranjero); Día Internacional del Trabajo ( $I^{\circ}$ de mayo); Fiesta Nacional ( $I^{\circ}$ de octubre). Esta estacionalidad produce un colapso en las estructuras turísticas y provoca una ineficiencia en el sector. En los últimos tiempos, el gobierno, consciente de la importancia de la industria del turismo para la economía, se está planteando flexibilizar el periodo vacacional.

Selección de los segmentos del mercado objetivo

a) Variables motivacionales:

- Motivación por actividades vinculadas al mar en un entorno natural y cultural con variadas ofertas

- Interés por conocer la cultura cubana, como sus fiestas, su música y sus bailes tradicionales, su arte culinario, etcétera

- Deseos de visitar los lugares históricos asociados a la figura del Che

- Interés por ambientes con diferentes categorías de protección ambiental y zonas proyectadas hacia el desarrollo sostenible

b) Variables demográficas:

- Personas jóvenes y adultas que buscan distracción y conocimiento sobre el entorno natural, cultural e histórico

- Clase media, con ingresos medios

- Jóvenes y adultos entre 20 y 50 años, con estadía promedio de tres a cuatro días en el destino 
Estrategia de posicionamiento

del destino Villa Clara en el mercado chino

Análisis corporativo interno

El análisis interno se fundamenta en el estudio descriptivo del estado actual del destino como condición para evaluar su potencial frente al entorno. En ese sentido, se realiza un diagnóstico integrado de los factores concurrentes sobre su estructura funcional, con el propósito de reconocer tanto los puntos fuertes como los débiles que identifican el contexto objeto de estudio.

De acuerdo con los factores considerados por el turista chino, el destino objeto de estudio tiene como fortalezas constituir un lugar seguro y limpio, con lugares interesantes -fundamentalmente naturales e históricos-, siendo las diferencias culturales de gran significación. Por lo tanto, el destino no debe promocionarse como de sol y playa específicamente, sino que deben potenciarse otros atributos de mayor atracción para el turista chino. Dado que el sol y las playas no constituyen un elemento muy llamativo para éste, pues implica exponerse a temperaturas relativamente altas -lo cual no es de su agrado, ya que cambia la coloración de su piel-, se torna vital promover el destino de manera integral, haciendo énfasis en los elementos singulares, como los monumentos históricos relacionados con la figura del Che, o también las Parrandas de Remedios, aunados a la oferta de la cayería norte, lo cual favorece un mejor posicionamiento en el mercado chino.

\section{Análisis competitivo}

El análisis externo se fundamenta en el estudio descriptivo que sintetiza la relación entre el destino y su entorno. Así pues, se valoran los factores externos que ejercen influencia significativa sobre la estrategia del destino, con el propósito de identificar las oportunidades y amenazas a que queda expuesto.

Con base en el análisis externo, se distinguen los factores de incidencia favorable sobre el destino en términos de oportunidades: localización geográfica en un entorno natural atractivo, con un agradable clima tropical cálido; buenas relaciones políticas y económicas entre los gobiernos de China y Cuba; expansión del mercado turístico emisor chino y un creciente interés de éste por conocer destinos con diferencias culturales; proximidad del destino Villa Clara a otros atractivos turísticos naturales y culturales (Trinidad, Cienfuegos); y Cuba como primer país de América al cual China le dio la categoría de ADS.

Entre los aspectos negativos en términos de amenazas, como condiciones externas que impone el entorno al destino, se identifican las siguientes: 
insuficiente reconocimiento internacional del espacio local y regional como destino turístico, lejanía respecto a China, ubicación en un entorno comercial potencialmente muy competitivo y exposición geográfica ante fenómenos meteorológicos severos (ciclones tropicales y frentes fríos).

Análisis de las posibilidades para una diferenciación efectiva de la competencia

El destino turístico Villa Clara debe posicionarse en el mercado turístico chino como de sol y playa con la presencia de singulares valores histórico-culturales que forman parte del enriquecido patrimonio cubano.

Atributos diferenciales de la competencia

a) Playas turísticas y fondos marinos vírgenes, con la singularidad de un ambiente natural exclusivo no masificado. En este destino se encuentra el mayor desarrollo turístico del polo, los Jardines del Rey de la Cayería Norte, conformados por Cayo Las Brujas, Ensenachos y Cayo Santa María, los cuales poseen una serie de atractivos relevantes: flora y fauna autóctona y endémica, terrestre y marítima; cálidas playas prácticamente en estado virgen, arena fina y blanca, arrecifes coralinos con una belleza increíble y exuberante vegetación de bosque manglar.

b) Existencia de ciudades histórico-culturales donde se atesora parte del rico patrimonio cubano

\section{SANTA Clara}

- Centro Histórico de la Ciudad. Ciudad capital o cabecera de provincia; fue trazándose a partir de la Plaza de Armas (Parque Leoncio Vidal, actual centro de la ciudad) según las Leyes de Indias,y este núcleo resultó desde sus inicios el centro de la actividad social, cultural y económica de la ciudad. Las construcciones se han ido modernizando a través de los años, aunque permanece gran parte de las estructuras iniciales, por lo que hoy predomina el eclecticismo en sus edificaciones (Lloret Feijóo et al., s/f). Cuenta con diversos sitios de interés histórico, cultural, arquitectónico 
Estrategia de posicionamiento

del destino Villa Clara en el mercado chino

y turístico, destacándose el Teatro La Caridad, donde se desarrollan los eventos culturales más importantes de la ciudad; la Casa de la Cultura, que promueve actividades para todas las edades y durante los doce meses del año; el Museo de Artes Decorativas, muy ligado al movimiento cultural, que lleva a cabo eventos como el afamado Longina (moderna trova); la Galería de Artes; la Biblioteca José Martí, joya arquitectónica donde se efectúan exposiciones y conciertos de artistas locales; el Mejunje, centro cultural que ha ganado reconocimiento nacional y de los turistas que visitan la ciudad, por su originalidad y la diversidad de actividades que tienen lugar todos los días de la semana, para cualquier gusto o preferencia; el Hotel Santa Clara Libre, también en el parque central, que en sus exteriores aún conserva el recuerdo de la lucha del pueblo por conseguir la victoria definitiva.

- Plaza Ernesto Che Guevara. Ubicada en el centro-oeste de la ciudad de Santa Clara. Obra arquitectónica concebida para rendir tributo al legendario guerrillero y a sus compañeros de lucha. Se inauguró el 28 de diciembre de 1988 para conmemorar el XXX Aniversario de la Batalla de Santa Clara (Lloret Feijóo et al., s/f) y hoy atesora en el mausoleo los restos del Che y sus compañeros; a un lado de la plaza se encuentra un museo donde se exponen objetos y fotos de él y de otros luchadores. En esta plaza se realizan las actividades políticas, patrióticas y militares más importantes, aunque también se desarrollan eventos culturales masivos, grandes conciertos o actos culturales; su uso principal es servir de espacio para el esparcimiento de los citadinos -como parque-, por su ambiente agradable y tranquilo y por el aire fresco que puede disfrutarse a lo largo del día. En las noches se llena de grupos de amigos, familias y parejas que van a pasar un buen rato y a compartir.

- Sitio Histórico del descarrilamiento, acción y toma del Tren Blindado y Loma del Capiro. El 29 de diciembre de 1958 las fuerzas rebeldes de la ciudad de Santa Clara descarrilaron el Tren Blindado y lograron la rendición de las tropas que allí venían. Este hecho fue un factor determinante para la victoria de la batalla de Santa Clara. El sitio de este acontecimiento hoy se considera Monumento Nacional y se ha convertido en un complejo conformado por cinco elementos escultóricos, así como cuatro vagones originales y el buldózer utilizado para levantar la vía férrea. Los 
vagones, que han sido ambientados en su interior, muestran imágenes de los sucesos, algunas de las pertenencias de las fuerzas que participaron en la batalla así como armas similares a las capturadas al enemigo (Lloret Feijóo et al., s/f).

REMEDIOS

- San Juan de los Remedios fue la octava Villa fundada en la isla el 24 de junio de 1545, hoy es considerada Monumento Nacional. La ciudad conserva aún sus viviendas, iglesias y edificios públicos, que muestran el nivel alcanzado por el artesanado criollo durante la Colonia y expresan el desarrollo socioeconómico, el modo de vida, las contradicciones de clases y los criterios estéticos de la población cubana a lo largo de cuatro siglos de historia. Este pueblo sufrió los constantes ataques y saqueos de corsarios y piratas. Es cuna de mitos y leyendas. Se honra, además, de ser la ciudad donde vivió y trabajó el brillante intelectual y compositor Alejandro Caturla.

- La Iglesia Parroquial Mayor, declarada igualmente Monumento Nacional desde 1949, y el Santuario de Nuestra Señora del Buen Viaje están ubicadas en la plaza central remediana, lo que le otorga la peculiaridad de ser única en Cuba con dos iglesias católicas, una frente a la otra, y además con una sólida y añeja devoción popular. Estos dos templos y las Parrandas son los atractivos más importantes de la ciudad. Las Parrandas son una de las tres fiestas nacionales cubanas -las otras dos son las Charangas de Bejucal y los Carnavales de Santiago de Cuba; se celebran cada 24 de diciembre; se diferencian del resto de las fiestas populares por los elementos artísticos que las enriquecen, por los efectos pirotécnicos y por la influencia que ejercen en la vida de los remedianos y los villaclareños, que, con sus características particulares, las han extendido a otros pueblos de la región.'

Atractivos de posicionamiento

Ambiente natural protegido, seguro y tranquilo; planta turística integrada a él; historia y vida cultural de la población.

'Lloret Feijóo et al., s/f y http://www.dtcuba.com/ShowReport.aspx?c=I53 [2009]. 
Estrategia de posicionamiento

del destino Villa Clara en el mercado chino

Desventajas para el posicionamiento

Imagen aún no consolidada sobre la base de la identidad del destino, deficiente desarrollo de las infraestructuras de apoyo y de la superestructura turística, e insuficiente comunicación promocional turística del destino. ${ }^{2}$

\section{Posibles destinos competidores y sus características}

Playa Santa Lucía de Cuba. Ubicada al sur del Canal Viejo de Bahamas, en medio de un entorno semidesolado, natural, virgen, paradisiaco. Tiene 20 kilómetros de playa arenosa de origen coralino. Sus aguas son muy tranquilas, ideales para el deporte náutico, la pesca superficial, la fotocaza submarina y los baños de mar.La profundidad mayor es de 1.8 metros. Posee una extensa barrera coralina, la segunda más grande del planeta luego de la australiana, y la mayor del hemisferio occidental, que la convierte en una gigantesca piscina. Los corales permiten conservar una gran variedad de peces y una flora marina envidiable para el buceo submarino y la pesca superficial. ${ }^{3}$

Cayo LaRgo del Sur. Considerada joya del archipiélago de los Canarreos, es una de las mejores islas para el buceo y las actividades náuticas. Tiene aproximadamente 300 cayos con 60 kilómetros de playas vírgenes, protegidas por hermosos arrecifes coralinos, con aguas poco profundas donde habitan gorgonias, peces y variada flora. También la Isla de la Juventud está incluida en este

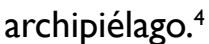

Este lugar cuenta con diferentes sitios para visitar: el Museo Cayo Largo del Sur, el Criadero de Tortuga, Playa Sirena, Cayo Iguana y los centros de buceo. Además de los deportes náuticos pueden realizarse múltiples actividades de entretenimiento, deportes en la playa, motocicletas y safaris para ver la flora y fauna de los cayos. ${ }^{5}$

VARADERO. Localizada en el punto más septentrional de la isla de Cuba, la playa deVaradero se extiende a lo largo de la estrecha península de Hicacos. Sus 22

\footnotetext{
${ }^{2}$ Con base en González Herrera (2008).

${ }^{3}$ http://www.camagueyrentals.com/camaguey-cuba/es/playa-santa-lucia-de-cuba/ [2009].

${ }^{4}$ http://www.islasperdidas.com/content/view/64/40/ [2009].

${ }^{5}$ http://www.excelenciastravel.com/DertinyDetails.aspx?id= 15 [2009].
} 
kilómetros de playa se caracterizan por tener una amplia franja de fina arena blanca y un suave descenso de su plataforma hacia el mar. ${ }^{6}$

Los fondos marinos de Varadero poseen más de 40 tipos de corales, una gran diversidad de peces, langostas, camarones, cangrejos, tortugas y más de 70 tipos de moluscos. Marinas como Chapelin, Dársena de Varadero y Gaviota garantizan las condiciones y medios para practicar el inmersionismo, con embarcaciones apropiadas, personal preparado, centros de enseñanza de buceo, cámaras hiperbáricas y el transporte necesario para cualquier emergencia.

Unas I4 000 habitaciones están disponibles para los vacacionistas que acuden cada año al lugar, distribuidas en hoteles de categorías de dos, tres, cuatro y cinco estrellas. Muchos de los hoteles en Varadero están gestionados por compañías foráneas. ${ }^{7}$

ARCHIPIÉLAGO JARDINES DEL REY. Este archipiélago se encuentra precisamente en la costa norte de la provincia Ciego de Ávila y forma parte del archipiélago Sabana-Camagüey, es el más grande de los cuatro archipiélagos de la isla de Cuba, con sus 2500 cayos e islitas. ${ }^{8}$ Es un destino que posee más de 30 kilómetros de playas vírgenes con grandes posibilidades para la práctica de buceo en sus fondos marinos, protegidos por la segunda barrera coralina más extensa del mundo. Es un joven sitio turístico con altos valores escénicos y ambientales y ecosistemas tropicales bien conservados.

Cayo Coco, ocupa el cuarto lugar en extensión en el archipiélago cubano, con un área de 370 kilómetros cuadrados y el atractivo adicional que ofrecen 22 kilómetros de excelentes playas, complementadas con una vegetación de manglares y cocoteros. Tiene también varias lagunas interiores, hábitat ideal para diversas especies de la fauna, $y$ dos interesantes senderos interpretativos: el de la duna de la Loma del Puerto y el de Las Dolinas.

Cayo Guillermo es uno de los de menor tamaño, con apenas 18 kilómetros cuadrados de extensión, aunque abundantes en una flora que incluye especies como la caoba, los almácigos y las sabinas. Sus tres playas -entre éstas Playa Pilar, considerada una de las más hermosas de la región- alcanzan una longitud de cuatro kilómetros y su valor escénico se refuerza con la existencia de otros

${ }^{6}$ http://es.wikipedia.org/wiki/Varadero [2009]; http://www.dtcuba.com/Pololnfo.aspx?pc=5 [2009].

${ }^{7}$ http://www.gran-caribe.com/espannol/varadero.asp [2009].

${ }^{8}$ http://www.cuba-rentacarros.com/hotel-jrey.php [2009]. 
Estrategia de posicionamiento

del destino Villa Clara en el mercado chino

elementos naturales como las dunas más altas del Caribe, que llegan hasta los 15 metros de altura. ${ }^{9}$

POLO TURÍSTICO DE HOLGUín. Uno de los más importantes destinos turísticos del país se halla en la región oriental, en Holguín, y es la singular playa de Guardalavaca. En sus predios existen extraordinarios atractivos naturales e infinidad de lugares de interés, desde hermosas playas de fina arena blanca y aguas transparentes verdeazules; preciosos senderos ecoturísticos y un parque con almácigos, yagrumas, tramos de manglares y maniguas costeras; hasta centenarios bosques donde habita el almiquí, raro mamífero cubano, considerado un fósil viviente.

\section{Principales competidores del Caribe}

Entre los principales competidores del Caribe se encuentran destinos como Cancún, República Dominicana, Jamaica, St. Kitts y Nevis, Barbados, St. Thomas, Granada, Puerto Rico, Aruba, Curazao y la Isla Margarita.

\section{Beneficios que se deben ofrecer a los clientes}

- Pequeña superficie del sistema insular, con relativo aislamiento geográfico y estado de naturalidad en la cayería norte

- Infraestructura constructiva integrada al ambiente natural

- Bajos costos de las operaciones turísticas, en relación con la competencia

- Atractivos naturales e histórico-culturales de excelente calidad, vinculados con la figura del Che, que garantizan una diversificación de la oferta

- Importante oferta para el turismo de salud en Elguea

- Población con alto nivel de instrucción y con una cultura local arraigada, fruto de las tradiciones históricas ${ }^{10}$

\footnotetext{
${ }^{9}$ http://www.dtcuba.com/ShowReport.aspx?c=27 [2009]; http://www.gran-caribe.com/espannol/ jardines_rey.asp_[2009].

${ }^{10}$ Con base en González Herrera (2008).
} 


\section{Articulación de la posición deseada en el mercado}

En correspondencia con los objetivos de la investigación, las estrategias para posicionar el destino turístico Villa Clara en el mercado turístico de China se enfocarán en potenciar los indicadores particulares de los cuales dispone el destino, mediante las acciones más factibles de implementar, dadas las particularidades de ese país.

\section{Elementos de la mezcla promocional}

PUBLICIDAD. La publicidad va a estimular la demanda del mercado objetivo por medio de un posicionamiento de Villa Clara como destino. La campaña de publicidad deberá ser creativa y contener lemas que comuniquen la amplia gama de productos, capaces de satisfacer las preferencias y expectativas del turista chino.

VENTA PERSONAL. La venta personal debe hacerse tanto con las agencias de viajes y mayoristas como con los turistas. Con el fin de lograr la venta de Villa Clara como destino, o bien como parte de un circuito, se deberá visitar a los turoperadores para ofrecer y dar a conocer los productos. Impartir seminarios especializados a los agentes y así estimular su conocimiento sobre los productos y servicios del destinoVilla Clara, certificando a aquellos que obtengan un amplio conocimiento de la oferta.

En cuanto a la venta personal con el turista, cuando se acerque la temporada de vacaciones en las principales ciudades emisoras de turismo (Beijing, Shanghai, Tianjin y Guangzhou), se deberán crear e instalar centros de información en aeropuertos y terminales de autobuses. Se brindará información sobre el destino y una guía de los prestadores de servicios. Se sugiere utilizar como apoyo monitores de televisión para transmitir videos sobre la riqueza turística disponible.

PROMOCIÓN DE VENTAS. Los objetivos de la promoción de ventas son:

- Posicionar el destino turístico de Villa Clara en el mercado chino

- Fortalecer la demanda turística hacia el destino turístico Villa Clara, dirigiendo la promoción hacia los segmentos definidos y las regiones emisoras más rentables 
Estrategia de posicionamiento

del destino Villa Clara en el mercado chino

- Impulsar los esfuerzos promocionales de los diversos actores beneficiados de la actividad turística del país a través de estrategias cooperativas

- Establecer programas de promoción continuos por cada producto turístico, que pongan énfasis en lo esencial y valioso de cada lugar y las posiciones como destino de alto valor agregado

- Estimular la producción y distribución de materiales informativos con las diferentes alternativas de viaje al destino Villa Clara y las características de sus recursos

- Consolidar los programas de relaciones públicas que permitan mejorar la imagen del destino turístico

- Propiciar la diversificación de los canales de distribución del destino turístico, que hagan posible una mejor comercialización y cobertura en el mercado objeto de estudio

- Afianzar los programas de mercadeo directo que propicien una mayor venta del producto turístico

Para el logro y cumplimiento eficiente de los objetivos planeados, se han definido estrategias y acciones, entre las que se destacan:

- Desarrollar un plan estratégico y de marketing de corto, mediano y largo plazo con base en la realización de estudios de mercado e inteligencia comercial en el mercado chino y sus segmentos, con objeto de establecer de forma efectiva el conjunto de estrategias de promoción de alta penetración y rentabilidad en las diferentes modalidades.

- Llevar a cabo campañas de promoción acordes con las expectativas del turista potencial, orientadas a la satisfacción de éste y al logro de resultados medibles de las acciones emprendidas.

- Establecer, con los recursos que se asignen, un desarrollo tecnológico que permita el uso intensivo de sistemas de información estratégica de mercados, en este caso el chino, con el propósito de contar con un amplio conocimiento de éste para ejecutar acciones.

- Potenciar la implantación de programas integrales de promoción en sus diferentes facetas (publicidad, relaciones públicas, mercadeo directo) especializando éstas por producto, temporada y segmento, enfocadas de manera prioritaria hacia los mercados de mayor demanda turística extranjera (Beijing, Shanghai, Tianjin y Guangzhou). 
- Desde la perspectiva de incrementar la participación de los diferentes agentes involucrados en el sector, promover la organización de programas cooperativos que, con la estrategia de inversiones conjuntas, implique al Ministerio del Turismo y a socios comerciales en acciones de promoción de productos en el mercado chino.

Bajo este esquema, es de vital importancia la participación activa de las agencias en el exterior y sería positiva la implicación del personal de negocios de la embajada cubana en China, para focalizar las oportunidades de coparticipación y colaboración, fundamentalmente turoperadores, proporcionando la información de inteligencia comercial y de las estrategias utilizadas por la competencia en este mercado.Además, se deben instrumentar estrategias para:

- Promocionar productos que potencien el turismo alternativo, ecológico, cultural, deportivo, de grupos y convenciones, entre otros, buscando que los posibles paquetes que se oferten otorguen valor agregado al destino turístico de Villa Clara, haciéndolo atractivo a las tendencias y características del mercado chino.

- Participar en ferias internacionales, principalmente en China, supervisando la decoración y abastecimiento de material promocional, a fin de proyectar de manera óptima la imagen del destino mediante el establecimiento de contactos de interés.

- Potenciar la promoción mediante las principales revistas de interés específico, mediante la gestión de una mayor cobertura de la oferta turística en artículos o secciones especiales.

- Establecer centros de información turística donde se promuevan y detallen las particularidades del polo turístico de Villa Clara.

- Informar sobre el destino turístico Villa Clara a los turistas potenciales por medio del envío de material promocional o correspondencia personalizada, con objeto de motivarlos a visitar el lugar.

RELACIONES PÚBLICAS. La finalidad de las relaciones públicas será generar una imagen positiva y atractiva del destino turístico Villa Clara, con sus recursos disponibles, para lo cual se propone, entre otras cosas, establecer contacto con aquellas empresas, turoperadores y organismos internacionales que se dedican a la inversión y comercialización de productos turísticos, junto con el 
Estrategia de posicionamiento

del destino Villa Clara en el mercado chino

Ministerio del Turismo y los encargados de negocios de la embajada cubana en China, para procurar que sea considerado este destino turístico.

Los medios que se recomiendan para alcanzar los objetivos trazados son:

- Periódicos: los anuncios pagados en los periódicos se usarán para dar información general de Cuba como destino turístico ideal del Caribe,y a Villa Clara dentro de éste; motivar al público hacia él y ofrecer ofertas turísticas de temporada.

- Revistas: se utilizarán revistas especializadas o sociales para llegar tanto al público objetivo como al potencial. Los anuncios en revistas deberán estar más enfocados hacia el segmento de turistas definido (entre 20 y 50 años), y así promocionar al destino Villa Clara como perfecto para el descanso y el contacto directo con la naturaleza, con hermosas playas y recursos culturales. También se podrán publicitar, por medio de ilustraciones y otras técnicas gráficas, zonas arqueológicas en los cayos y zonas propicias para el desarrollo de otras modalidades turísticas.

- Radio: deberán crearse spots de 20 a 30 segundos de duración para promocionar los recursos turísticos disponibles, así como actividades culturales, artísticas o sociales que puedan contribuir al fomento de flujos turísticos.

- Televisión: se deberá elaborar un breve anuncio informativo que, de manera concisa y estimulante, muestre las características y los beneficios turísticos del destino, a fin de crear interés y deseo de visita en el espectador.

- Anuncios espectaculares: son muy útiles como herramientas de comunicación en ciudades grandes como Beijing, Shanghai,Tianjin, Guangzhou, entre otras, y deberán diseñarse varias versiones para promocionar productos turísticos específicos de Villa Clara, con énfasis en la emblemática figura del Che y en las hermosas playas del lugar.

- Internet:al ser un medio cada día más utilizado, deberán crearse páginas electrónicas para ser consultadas en línea en los buscadores más demandados y en sitios electrónicos especializados en turismo.

- Pósters y folletos: se distribuirán y colocarán en agencias de viajes, en terminales de autobuses o en aeropuertos.

- Cartelería: hay muchas posibilidades a pequeña escala:colocar carteles que comuniquen valores, que muestren novedades del destino, que incorporen 
imágenes, etc., en lugares concurridos de las principales ciudades emisoras de turismo.

- Buzoneo y reparto: la entrega de folletos creativos e impactantes en un radio de acción determinado puede ser efectiva y económica.

- Mailing: este método sólo es recomendable si se crea una base de datos que se mantenga actualizada y personalizada. Es conveniente seleccionar un grupo reducido de clientes, enviar más de una carta y procurar generar una respuesta a corto plazo.

- Presentación del destino: los books del destino, CD-ROM con forma de tarjeta de visita, videos demostrativos, catálogos, entre otros, son soportes básicos y útiles para la mayoría de los destinos que se promocionan en busca de mejor posicionamiento. Innovar en sus formatos y muestras de contenido es una de las claves del éxito publicitario de estos medios.

- Ferias: si no es posible contratar un stand, una opción rentable es tener presencia con azafatas que repartan información y tratar de conseguir nuevos clientes utilizando el reclamo de un regalo promocional.

- Newsletter: es una forma barata de comunicarse periódicamente, vía correo electrónico, con clientes actuales y potenciales. Permite captarlos, fidelizarlos y fomentar la demanda del destino, así como el conocimiento de éste.

- Colaboraciones: proponer la visita al destino como forma de pago a los medios de comunicación y a los socios de promociones conjuntas en el mercado chino.

Entre las estrategias complementarias para posicionar al destino turístico Villa Clara en el mercado chino se encuentran:

- Atraer grandes eventos nacionales e internacionales de carácter comercial, industrial, cultural, deportivo, artístico y de enseñanza; para materializar esta estrategia se debe, por un lado, contratar agencias de investigación para adquirir listas de clientes potenciales con interés en realizar eventos, $y$, por el otro, asegurar un rol protagónico del Estado cubano en actividades para fomentar la imagen de Villa Clara y de su posición como principal agente impulsor del desarrollo turístico.

- Desarrollar las posibilidades del turismo deportivo en el destino y en su entorno provincial. 
Estrategia de posicionamiento

del destino Villa Clara en el mercado chino

- Potenciar más el logro de acontecimientos deportivos puntuales y crear competencias periódicas con la participación internacional.

- Promover a Villa Clara y su ámbito provincial como destino turístico relacionado con el deporte y la aventura.

- Aumentar el número de acontecimientos culturales periódicos que singularicen la ciudad respecto a otros destinos de turismo cultural (las Parrandas de Remedios, las Parrandas de Camajuaní, el Festival de la Trova de Santa Clara).

MARKETING DIRECTO. Se podrá elaborar una base de datos con ayuda de los hoteles para mandar información sobre actividades y ofertas en el destino tanto a los turistas que lo han visitado como al vasto mercado potencial existente en China, a fin de motivarlos para su primera visita o sucesivas.

\section{Plan de acción}

Para el logro de los objetivos planteados, que toman como eje temático fundamental el posicionamiento y la promoción efectivos del destino en el mercado turístico emisor chino, se proponen las siguientes acciones:

a) Participar en ferias, festivales gastronómicos, seminarios, talleres, viajes de familiarización y para la prensa (press tours) y colocar publicidad de la oferta turística en los medios de comunicación más importantes. Las ferias de particular interés, ya que implican no sólo a las organizaciones que gestionan el turismo emisor chino, sino también de otros destinos, son: Beijing International Travel and Tourism Market; Guangzhou International Travel Fair, feria especializada que se celebra en Cantón; China International Travel Mart (CITM), que se desarrolla en la ciudad de Kunming; International Travel Expo Hong Kong; China Travel Mart en Shangai.

b) Llevar a cabo un taller-seminario sobre las potencialidades turísticas de Villa Clara en las ciudades de Beijing, Shangai y Hong Kong, porque ahí se ubican los principales operadores.

c) Organizar, por parte de la embajada cubana, exposiciones en museos o lugares altamente frecuentados relacionados con la imagen del Che $y$ con los atractivos naturales de los cuales dispone el destino. 
Los implicados en estas acciones son: Cubanacán S.A.; Gaviota S.A.; Ministerio del Turismo; Embajada cubana en China; Cadena hotelera Sol Meliá; y turoperadores actuales del polo turístico, sobre todo los de la cayería norte.

\section{Conclusiones}

La investigación desarrollada permitió arribar a las siguientes conclusiones:

I. El turismo chino ha experimentado un acelerado crecimiento como destino turístico y se ha constituido en un mercado emisor con alto potencial de desarrollo. Las principales causas son, entre otras, el aumento del poder adquisitivo, el envejecimiento de la población, la ventaja en el tipo de cambio y las altas tasas de ahorro.

2. Es necesario orientar el desarrollo de estrategias para posicionar a Villa Clara en el mercado turístico chino, como un magnífico destino turístico de sol y playa con la presencia de singulares valores histórico-culturales que forman parte del enriquecido patrimonio cubano.

3. Entre las fortalezas se encuentran la imagen asociada con la figura del Che, lo cual le da un distintivo único a la ciudad de Santa Clara, materializado en sus monumentos; así como la seguridad y tranquilidad presentes. Mientras que entre las debilidades están tanto la escasa promoción de los recursos turísticos como una red hotelera en la ciudad de Santa Clara carente de atractivos y de diversificación, y baja calidad y poca variedad de servicios turísticos.

4. Los factores que considera más relevantes el turista chino al seleccionar un destino son la seguridad y la limpieza del lugar, el grado de interés que éste proporciona, el acercamiento a una cultura diferente, el contacto directo con la naturaleza y el conocimiento de sitios históricos.

5. Las principales desventajas para el posicionamiento del destino son la existencia de una imagen aún no consolidada sobre la base de la identidad del destino, un deficiente desarrollo de las infraestructuras de apoyo y de la superestructura turística, y una insuficiente comunicación promocional turística del destino.

6. El segmento de mercado está representado por personas jóvenes y adultas, de entre 20 y 50 años, de clase media, con ingresos medios, que buscan distracción y conocimiento sobre el entorno natural, cultural e histórico. 
Estrategia de posicionamiento

del destino Villa Clara en el mercado chino

7. La aplicación del procedimiento permitió elaborar un conjunto de estrategias viables para posicionar la oferta del destino turísticoVilla Clara en el mercado chino, como alternativa para incrementar la demanda.

\section{FUENTES CONSULTADAS}

ACNielsen (2005). "Understanding the Chinese Traveller", septiembre de 2005.

Bigné Alcañiz, E., X. Font y L. Andreu (2000). Marketing de destinos turísticos. Madrid: ESIC.

Boletín Semanal de la Industria Turística Cubana. DTCuba.com. Disponible en: http://www.dtcuba.com/ShowReport.aspx?c=27. En línea 2009.

Camisón, C. y V. Monfort ( 1998). "Estrategias de reposicionamiento para destinos turísticos maduros: el caso de la Costa Blanca". Estudios Turísti$\cos , 135,5-28$.

Esteban Talaya,A. (1996). Principios de marketing. Madrid: ESIC.

González Herrera, M. (2008). "Planificación estratégica del desarrollo sostenible en destinos turísticos de sol y playa. Cayo Las Brujas, Cuba". Itinerarium, I [en línea]. Disponible en:http://seer.unirio.br/index.php/ itinerarium/article/viewPDFInterstitial/I40/III.

Iglesias Tovar,J.R. (I998). Comercialización de productos y servicios turísticos. Madrid: Síntesis.

López Alberca, D. (2006). Estudio de China como turismo emisor. Madrid: Ediciones Promadrid.

Lovelock, C. (1997). Mercadotecnia de un servicio. Trad. Guadalupe Meza Staines, $5^{a}$ ed. México: Prentice Hall Hispanoamericana.

Lloret Feijoó, M.C., et al. (s/f). El Turismo y su incidencia en el desarrollo local de Villa Clara, Cuba, en Eumed.net, Biblioteca Virtual de Derecho, Economía y Ciencias Sociales [en línea]. Disponible en:http://www.eumed. net/libros/2007b/29l//3.htm [consultado en 2009].

OMT (1996). Manual de economía turística. Madrid: Organización Mundial del Turismo.

(2006). Tendencias de los mercados turísticos: panorama mundial y actualidad del turismo 2005. Madrid: Organización Mundial del Turismo, $176 \mathrm{p}$.

Porter, M.E. (1998). Ventaja competitiva. México: CECSA. 


\section{ANEXO}

Procedimiento para el desarrollo de una estrategia de posicionamiento en el mercado propuesto por Lovelock (1997)

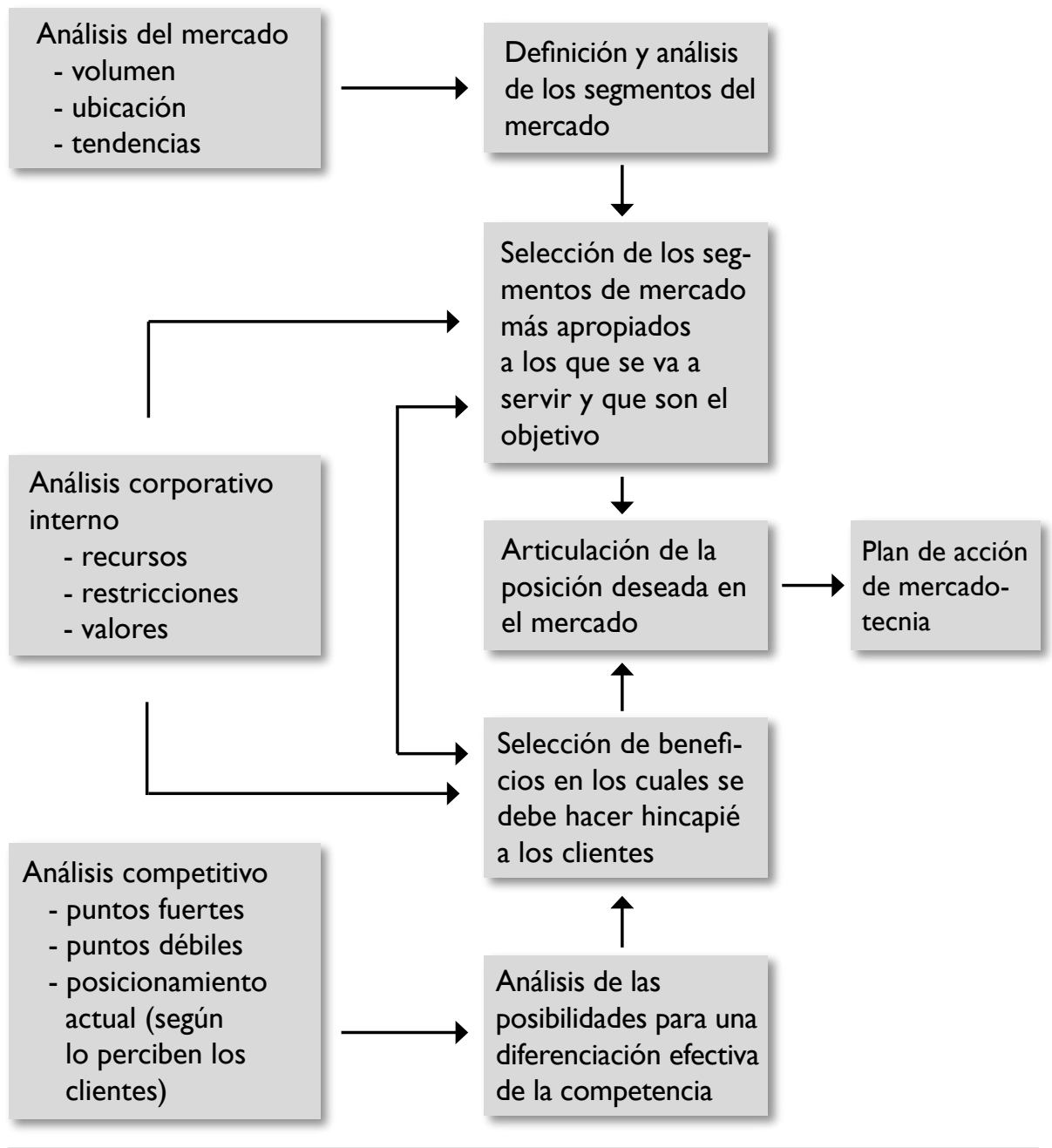

Fuente: Christopher Lovelock (1997). Mercadotecnia de un servicio.Trad. Guadalupe Meza Staines, $5^{a}$ ed., México: Prentice Hall Hispanoamericana. 